Fatherree, T. J., and Allen, E. V. (1938). Arch. intern. Med., 62, 1015. Freemen, N. E. (1935). Amer. F. Physiol., 113, 384.

- Smithwick, R. H., and White, J. C.' (1934). Ibid., 107, 529.

Gaskell Zeller, J. W.' (1937). Ibid., 120, 475 .

Gibbon

Handelsman, M. B., Levitt, L. M., and Conrad, H. (1952). Amer. F. med. Sci., 224,34

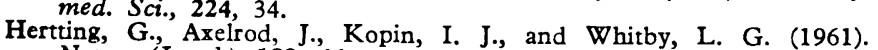
Nature (Lond.), 189, 66

Hickler, R. B., Thompson, G. R., Fox, L. M., and Hamlin, J. T. (1959). Nesw Engl. 7. Med., 261, 788 .

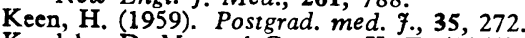

Kerslake, D. M., and Cooper, K. E. (1950). Clin. Sci., 9, 31.

Martin, M. M. (1953). Lancet, 1, 560.

Megibow, R. S., Megibow, S. J., Pollack, H., Bookman, J. J., and

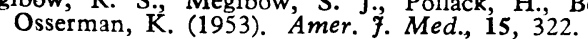

Meltzer, S. J., and Meltzer, C. (1903). Amer. 7. Physiol., 9, 252. Mendlowitz, M., Grossman, E. B., and Alpert, S. (1953). Amer. F. Med., $15,316$.

Meyer, R. T. (1941). Helv. med. Acta, 8, Suppl. No. 7, 18.

Odel, H. M., Roth G. M., and Keating, F. R. (1955). Diabetes, 4, 92.

Pickering, G. W. (1932). Heart, 16, 115.

Pickering, G. W. (1932). Hear 1 .

Pryce, T. D. (1887). Ibid., 2, 11

(1893). Brain, 16, 416 .

Richards, R. L. (1946). The Peripheral Circulation in Health and Disease. Livingstone, Edinburgh.

Rundles, R. W. (1945). Medicine (Baltimore), 24, 111.

Sharpey-Schafer, E. P., and Taylor, P. J. (1960). Lancet, 1, 559.

Shumacker, H. B. (1942). Bull. Fohns Hopk. Hosp., 71, 1.

Stone, D. B., Talley, R. B., and Eckstein, J. W. (1961). Circulation, 24, 1051.

Wilkins, R. W., and Kolb, L. C. (1941). Amer. 7. med. Sci., 202, 216.

\title{
In Vitro Thrombosis and Platelet Aggregation in Myocardial Infarction
}

\author{
N. G. ARDLIE,* M.B., B.S. ; RAELENE L. KINLOUGH, $†$ M.B., B.S. \\ C. J. SCHWARTZ, ${ }^{*}$ M.D., M.R.A.C.P., M.C.P.A., M.C.PATH.
}

Brit. med. F., 1966, 1, 888-891

In 1958 Chandler showed that when recalcified citrated whole blood is made to flow in a closed rotating circular plastic loop it does not clot but forms a discrete mass with the histological features of a thrombus. This observation, confirmed by Poole (1959), prompted us to employ the Chandler tube in an attempt to determine if the circulating blood of patients with, after, or prone to thrombosis shows any propensity to abnormal thrombosis in vitro. As part of such a study we report our observations on 50 patients with myocardial infarction and 52 healthy controls.

\section{Materials and Methods}

Subjects Studied.-The age distribution of the 102 subjects studied is detailed in Table I. Control subjects consisted of our colleagues, laboratory assistants, and volunteer hospital porters in whom there was neither clinical nor electrocardiogaphic evidence of myocardial infarction. Patients with myocardial infarction were selected from both hospital in-patient and outpatient clinics, and all had clinical, laboratory, and electrocardiographic evidence consistent with this diagnosis. Ten of the 50 patients with myocardial infarction and 6 of the 52 controls were women, numbers which were too small to permit a separate sex analysis. Most subjects were studied for six or seven consecutive days.

Blood Samples.-Antecubital venous blood was collected each morning, with the aid of venous occlusion and mild forearm exercise, by means of siliconized glass syringes and 19-gauge needles. Nine parts of blood were added to one part of $3.8 \%$ trisodium citrate in siliconized glass centrifuge tubes, and were mixed gently by inversion. Citrated platelet-rich plasma was prepared by centrifuging at $350 \mathrm{~g}$ for 15 minutes. On the first day of study samples for total serum cholesterol and plasma fibrinogen were collected.

Total serum cholesterol was estimated with a Technicon Auto-Analyzer, a slight modification of the method described by Zlatkis, Zak, and Boyle (1953) being used.

Plasma fibrinogen was determined by the method of Soles and Roman (1957).

\footnotetext{
- Department of Pathology, Institute of Medical and Veterinary Science, Adelaide, South Australia.

$\uparrow$ Department of Medicine, University of Adelaide, South Australia.
}

The Chandler apparatus was essentially similar to that first described by Chandler in 1958 and subsequently modified by Poole (1959). A circular disk of perspex was attached to a larger perspex disk inclined at 30 degrees from the horizontal and mounted on an electrically driven motor rotating at 9 r.p.m.

One millilitre of citrated whole blood or platelet-rich plasma was placed in a closed circular loop of polyvinyl chloride tubing (Portex, NT/F) having an internal bore of $3 \mathrm{~mm}$. This was recalcified by the addition of $0.1 \mathrm{ml}$. of $\mathrm{M} / 4$ calcium-chloride solution, at which time a stopwatch was started. The tube was closed with a short cuff of slightly larger tubing (Portex, $\mathrm{NT} / \mathrm{K}$ ), the closed loop fitted around the smaller perspex disk, and the motor started. The latter disk had a short recess to accommodate the cuff. Each loop had a length of $37.9 \mathrm{~cm}$. $(r=6 \mathrm{~cm}$.), and with rotation the column of blood or plasma had a constant linear velocity of $340 \mathrm{~cm}$. $/ \mathrm{min}$. A fixed protractor was mounted beneath the perspex disks, and the angle of the advancing column of blood or plasma was recorded at 30 -sec. intervals. Changes occurring at the advancing edge were observed through a wide-angle stereoscopic dissecting microscope under bright oblique illumination.

All experiments were performed at room temperature maintained within the range $22-25^{\circ} \mathrm{C}$.

Thrombus Formation Time.-This term, coined by Connor and Poole (1961), relates to the time at which the angle of the advancing edge of blood or plasma changed.

Whole-blood Thrombus Length.-In all cases rotation continued for seven minutes after an angle change had occurred. The thrombus formed was emptied into a Petri dish containing $0.9 \%$ saline, and its length was measured to the nearest milli-

TABLE I.-Age Distribution of the 102 Subjects Studied. Patients with Myocardial Infarction are Subdivided Into Those Receiving or not Receiving Anticoagulant Therapy

\begin{tabular}{|c|c|c|c|c|c|c|c|}
\hline \multirow{2}{*}{$\begin{array}{c}\text { Subject } \\
\text { Categories }\end{array}$} & \multicolumn{7}{|c|}{ Age Group (years) } \\
\hline & $11-20$ & $21-30$ & $31-40$ & $41-50$ & $51-60$ & $61-70$ & $71-80$ \\
\hline Controls & 3 & 9 & 12 & 15 & 10 & 3 & - \\
\hline $\begin{array}{c}\text { Myocardial infarct: } \\
\text { Anticoagulant } \\
\text { No anticoagulant } \\
\end{array}$ & $\overline{1}$ & - & 1 & $\begin{array}{l}4 \\
1 \\
\end{array}$ & $\begin{array}{r}15 \\
4 \\
\end{array}$ & $\begin{array}{r}3 \\
14 \\
\end{array}$ & $\begin{array}{l}1 \\
6 \\
\end{array}$ \\
\hline $\begin{array}{l}\text { Total myocardial } \\
\text { infarct } \ldots\end{array}$ & 1 & - & 1 & 5 & 19 & 17 & 7 \\
\hline
\end{tabular}


metre. Mean thrombus length for each patient was the mean of the values obtained on each of the days studied.

Whole-blood Thrombus Weight.-After fixation in $10 \%$ formalin the thrombi were blotted dry between filter papers and weighed to the nearest milligram. Mean thrombus weight for each patient was again the mean of the values obtained on each of the days studied.

Platelet Aggregation.-Platelet-rich plasma was observed in the transparent plastic tube through a dissecting microscope at 12 magnifications. The time at which visible platelet aggregates formed, and their number, size, and time of persistence, were recorded. Three patterns of spontaneous platelet aggregation were recognized:

(a) Normal pattern was defined as a sporadic appearance and disappearance of visible aggregates rarely exceeding one or two in number and persisting only for one minute or less before a change in the angle of the advancing column of plasma occurred. Just before this angle change there was invariably a rapid and dramatic rise in the number of aggregates, which increased in size and coalesced to form a solid mass at the advancing edge.

(b) Persistence was defined as the continuous presence of visible platelet aggregates for a minimum of four minutes. In many cases aggregates formed within one or two minutes of recalcification and persisted throughout the experiment.

(c) "Snowstorm" phenomenon was defined as the formation of hundreds or thousands of small platelet aggregates often within one to two minutes of recalcification. These invariably persisted for at least four minutes. On a number of occasions the process was either completely or partially reversible. This phenomenon should not be confused with the large number of aggregates seen normally just prior to a change in the angle of the advancing column of plasma.

\section{Results}

Whole-blood Thrombus Length and Weight.-Figs. 1 and 2 show the mean thrombus length (mm.) and mean thrombus

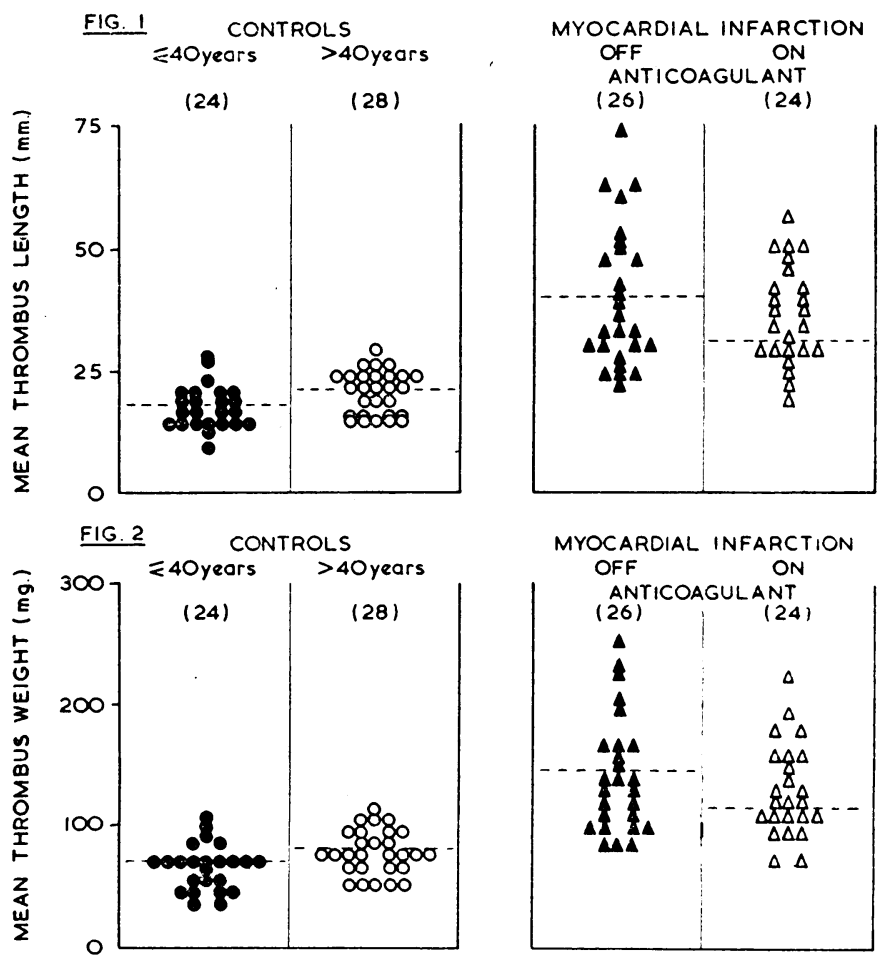

Fig. 1.- Mean thrombus length ( $\mathrm{mm}$.) in control subjects aged 40 or less and over 40 , and in patients with myocardial infarction subdivided into those receiving and not receiving anticoagulant therapy. The number of subjects in each group is indicated at the top of each column. FIG. 2. - Mean thrombus weight (mg.) in control subjects aged 40 or less and over 40 , and in patients with myocardial infarction subdivided into those receiving and not receiving anticoagulant therapy. The number of subjects in each group is indicated at the top of each column. weight (mg.) in control subjects and patients with myocardial infarction. The control subjects were divided into two age groups, under and over 40 years, while patients with myocardial infarction were subdivided into those receiving or not receiving anticoagulant therapy.

Thrombus length and weight tended to increase with age in healthy subjects. Further, there was a marked increase in both thrombus length and weight in patients with myocardial infarction when these were compared with controls over 40 years of age. It can also be seen that, in patients with myocardial infarction, thrombus weight and length showed a tendency to be less in those receiving anticoagulant therapy.

Effect of Time After Infarction.-Fig. 3 A and B shows mean thrombus length ( $\mathrm{mm}$.) and mean thrombus weight (mg.) in patients with myocardial infarction analysed according to the time after infarction and the presence or absence of anticoagulant therapy. Thrombus length and weight clearly declined with the passage of time after infarction, irrespective of the presence or absence of anticoagulant therapy. In patients

(A)

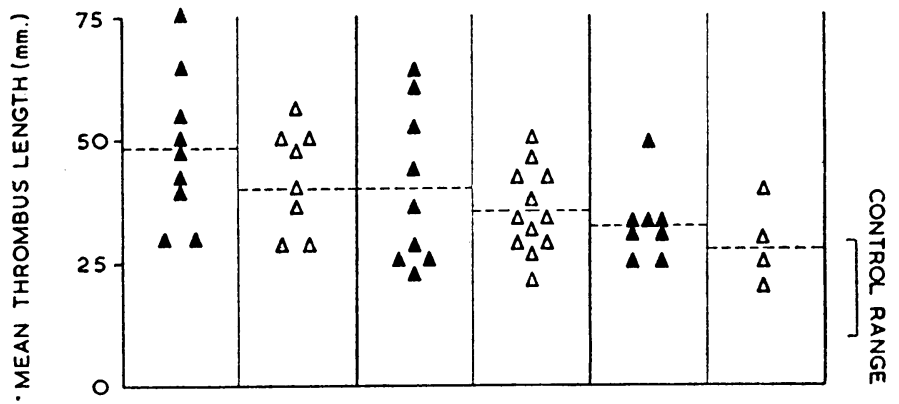

(B)

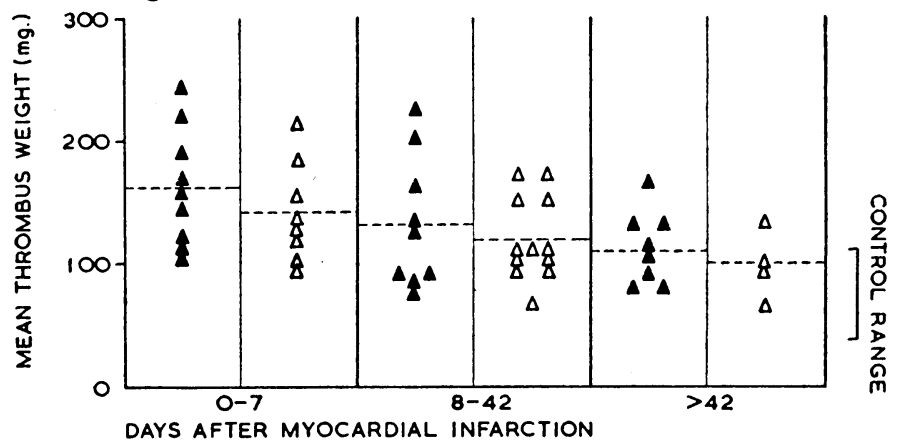

Fig. 3.-(A) The mean thrombus length ( $\mathrm{mm}$.) and (B) the mean thrombus weight (mg.) in patients with myocardial infarction are analysed according to time after infarction and the presence $(\triangle)$ or absence $(\triangle$ of anticoagulant therapy. The range of values for thrombus length and weight in control subjects over 40 years of age is indicated on the right of each figure.

six or more weeks after the clinical event the values for thrombus length and weight returned to within the normal range in only 7 of the 12 subjects studied. Further, thrombus length and weight in each of the main subdivisions were consistently, though only slightly, less in those patients receiving anticoagulant therapy.

Plasma Fibrinogen and Thrombus Size.-Plasma fibrinogen levels were found to be raised in patients with myocardial infarction. Both in these patients and in control subjects we found a statistically significant correlation between the plasma fibrinogen level on the one hand and thrombus weight on the other. In the case of patients with myocardial infarction the calculated correlation coefficient $r$ was $0.7180(P<0.001)$, and in the controls $\mathrm{r}$ was $0.4136(\mathrm{P}<0.01)$.

Total Serum Cholesterol and Thrombus Size.-Neither in patients with myocardial infarction nor in healthy controls 
(Fig. 4) did we find a significant correlation between thrombus weight and the total serum cholesterol level.

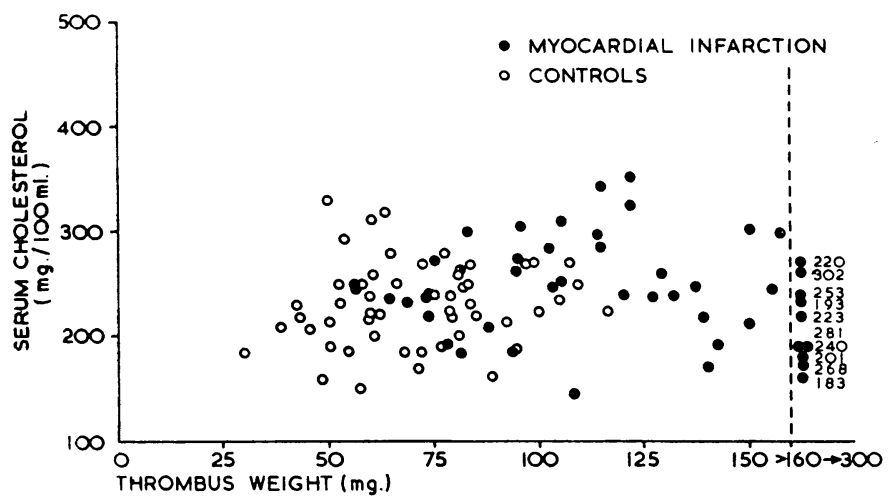

FIG. 4.-Mean thrombus weight (mg.) plotted against total serum cholesterol (mg./100 ml.) in patients with myocardial infarction (O) and in control sub;ects (O).

Thrombus Formation Time.-In patients with myocardial infarction both the whole blood and plasma thrombus formation times did not differ significantly from those of controls over the age of 40 years. There was no prolongation of the thrombus formation time in patients with myocardial infarction receiving oral anticoagulant therapy, a finding which is not in agreement with the results of Cunningham, McNicol, and Douglas (1965).

\section{Platelet-rich Plasma}

In control subjects aged 40 and less the normal pattern (see Methods) of platelet aggregation was observed in $98.6 \%$ of days studied (Table II). In none of the subjects in this age group was the snowstorm phenomenon of platelet aggregation observed. Abnormal platelet aggregation in the young controls was found therefore with an overall frequency of only $1.4 \%$ of the total days (142) studied. In controls over 40 years of age abnormal persistence of platelet aggregates was noted in $4.3 \%$ of 161 days studied. In addition, the snowstorm phenomenon occurred on $2.5 \%$ of days studied, giving a total of $6.8 \%$ of days showing abnormal platelet aggregation. This tendency

TABLE II.-Frequency (Expressed as a Percentage of the Number of Days Studied) of the Two Patterns of Abnormal Platelet Aggregation Considered Separately and Together, in Controls Aged 40 or Less and Those Over 40, and in Patients with Myocardial Infarction Subdivided Into Those Receiving and Not Receiving Anticoagulant Therapy, and Combined

\begin{tabular}{|c|c|c|c|c|}
\hline $\begin{array}{l}\text { Subject } \\
\text { Categories }\end{array}$ & $\begin{array}{l}\text { Days } \\
\text { Studied }\end{array}$ & $\begin{array}{c}\text { Persistence } \\
(\%)\end{array}$ & $\begin{array}{c}\text { Snowstorm } \\
\text { Phenomenon } \\
(\%)\end{array}$ & $\begin{array}{c}\text { Total Platelet } \\
\text { Abnormality } \\
(\%)\end{array}$ \\
\hline $\begin{array}{l}\text { Controls } ₹ 40 \text { years } \\
\text { Controls }>40 \text { years }\end{array}$ & $\begin{array}{l}142 \\
161\end{array}$ & $\begin{array}{l}1 \cdot 4 \\
4 \cdot 3\end{array}$ & $\begin{array}{l}0 \cdot 0 \\
2 \cdot 5\end{array}$ & $\begin{array}{l}1 \cdot 4 \\
6 \cdot 8\end{array}$ \\
\hline $\begin{array}{l}\text { Myocardial infarct: } \\
\text { On anticoagulant } \\
\text { No anticoagulant }\end{array}$ & $\begin{array}{l}148 \\
169\end{array}$ & $\begin{array}{l}16 \cdot 2 \\
20 \cdot 7\end{array}$ & $\begin{array}{r}11 \cdot 5 \\
4.7\end{array}$ & $\begin{array}{l}27 \cdot 7 \\
25 \cdot 4\end{array}$ \\
\hline $\begin{array}{c}\text { Myocardial infarct } \\
\text { combined }\end{array}$ & 317 & $18 \cdot 6$ & 7.9 & 26.5 \\
\hline
\end{tabular}

for the frequency of spontaneous platelet aggregation to increase with age in control subjects was found to be statistically significant $(0.01>\mathrm{P}<0.05)$.

In contrast to the findings in control subjects, abnormal platelet aggregation was observed in patients with myocardial infarction with an overall frequency of $26.5 \%$ of 317 days studied (Table II). Persistence accounted for $18.6 \%$, and the snowstorm phenomenon for $7.9 \%$ of the days studied showing abnormal platelet aggregation. Table II also shows the percentage prevalence of days of abnormality in patients with and without anticoagulant therapy. The overall frequency of abnormal platelet aggregation was found to be $27.7 \%$ and $25.4 \%$ in patients on and off anticoagulants respectively, a difference which was not statistically significant. Persistence occurred less often in patients receiving anticoagulants $(16.2 \%)$ than in those not receiving anticoagulants $(20.7 \%)$, a difference which did not attain statistical significance. The snowstorm phenomenon was more frequent in patients on anticoagulants $(11.5 \%)$ than in those not receiving anticoagulants $(4.7 \%)$. This trend did not, however, attain statistical significance.

The frequency of abnormal platelet aggregation has also been considered in relation to the time after infarction (Table III). It can be seen that the overall frequency of platelet abnormality was practically the same at $0-7$ days $(29.3 \%)$ and $8-42$ days $(29.9 \%)$, but in patients six or more weeks after infarction the number of days showing abnormality had decreased to $18.7 \%$. When the two patterns of abnormal platelet aggregation are considered separately (Table III) it is apparent that the frequency of persistence $0-7$ days after infarction $(21.2 \%)$ was similar to the frequency at $8-42$ days $(20.5 \%)$ after infarction, but in patients who had sustained infarcts more than six weeks before the time of study only $13.2 \%$ of days studied showed this pattern. The frequency of the snowstorm phenomenon varied from $8.1 \%$ at $0-7$ days to $9.4 \%$ at $8-42$ days, while in patients with infarcts over six weeks old the number of days studied showing this phenomenon decreased to $5.5 \%$. It is of interest to note that neither persistence nor the snowstorm phenomenon was observed in anticoagulated patients six or more weeks after infarction. In this group only four subjects were studied for a total of 25 days. We are therefore reluctant to draw any final conclusions from this latter observation.

\section{Discussion}

We have found that the thrombi produced in the Chandlet apparatus with blood from patients after myocardial infarction are both longer and heavier than the thrombi of control subjects having neither clinical nor electrocardiographic evidence of infarction. Thrombus size clearly decreases with the passage of time after infarction, and tends to be less in those patients receiving anticoagulant therapy (Fig. $3 \mathrm{~A}$ and $\mathrm{B}$ ). Both in the control subjects $(\mathrm{P}<0.01)$ and in patients with myocardial infarction $(\mathrm{P}<0.001)$ thrombus weight and the plasma fibrinogen levels showed statistically significant correlations. It is well known that the plasma fibrinogen level is elevated in patients after myocardial infarction (McDonald and Edgill,

TABle III.-Frequency (Expressed as a Percentage of the Number of Days Studied) of the Two Patterns of Abnormal Platelet Aggregation (Considered Separately and Together), According to Time After the Event, in Patients with Myocardial Infarction, the Latter Being Subdivided Into Those Receiving and Not Receiving Anticoagulant Therapy, and Combined

\begin{tabular}{|c|c|c|c|c|c|c|c|c|c|c|c|c|c|}
\hline \multirow{3}{*}{\multicolumn{2}{|c|}{ Myocardial Infarct Category }} & \multicolumn{10}{|c|}{ Time After Infarction (Days) } & \\
\hline & & \multicolumn{4}{|c|}{$0-7$} & \multicolumn{4}{|c|}{$8-42$} & \multicolumn{2}{|c|}{$>42$} & & \\
\hline & & $\begin{array}{c}\text { Days } \\
\text { Studied }\end{array}$ & $\begin{array}{c}\text { Per- } \\
\text { sistence } \\
(\%)\end{array}$ & $\begin{array}{l}\text { Snow- } \\
\text { storm } \\
\text { Pheno- } \\
\text { menon } \\
(\%)\end{array}$ & $\begin{array}{c}\text { Total } \\
\text { Platelet } \\
\text { Abnor- } \\
\text { mality } \\
(\%)\end{array}$ & $\begin{array}{l}\text { Days } \\
\text { Studied }\end{array}$ & $\begin{array}{c}\text { Per- } \\
\text { sistence } \\
(\%) \\
\%\end{array}$ & $\begin{array}{c}\text { Snow- } \\
\text { storm } \\
\text { Pheno- } \\
\text { menon } \\
(\%)\end{array}$ & $\begin{array}{c}\text { Total } \\
\text { Platelet } \\
\text { Abnoor- } \\
\text { mality } \\
(\%)\end{array}$ & $\begin{array}{l}\text { Days } \\
\text { Studied }\end{array}$ & $\underset{\substack{\text { Per- } \\
\text { sistence } \\
(\%)}}{ }$ & $\begin{array}{l}\text { Snow- } \\
\text { storm } \\
\text { Pheno- } \\
\text { menon } \\
(\%)\end{array}$ & $\begin{array}{c}\text { Total } \\
\text { Platelet } \\
\text { Abnor- } \\
\text { mality } \\
(\%)\end{array}$ \\
\hline $\begin{array}{l}\text { On anticoagulant } \\
\text { No anticoagulant }\end{array}$ & .. & $\begin{array}{l}47 \\
52\end{array}$ & $\begin{array}{l}21 \cdot 3 \\
21 \cdot 2\end{array}$ & $\begin{array}{r}14.9 \\
1.9\end{array}$ & $\begin{array}{l}36 \cdot 2 \\
23 \cdot 1\end{array}$ & $\begin{array}{l}76 \\
51\end{array}$ & $\begin{array}{l}18.4 \\
25 \cdot 5\end{array}$ & $\begin{array}{r}13 \cdot 2 \\
3.9\end{array}$ & $\begin{array}{l}31 \cdot 6 \\
27.5\end{array}$ & $\begin{array}{l}25^{*} \\
66\end{array}$ & $\begin{array}{l}0 \cdot 0^{*} \\
18 \cdot 2\end{array}$ & $\begin{array}{l}0.0 * \\
7.6\end{array}$ & $\begin{array}{l}0.0^{*} \\
25.8\end{array}$ \\
\hline Combined .. & .. & 99 & $21 \cdot 2$ & $8 \cdot 1$ & $29 \cdot 3$ & 127 & $20 \cdot 5$ & $9 \cdot 4$ & $29 \cdot 9$ & 91 & $13 \cdot 2$ & 5.5 & 18.7 \\
\hline
\end{tabular}

- Only four patients in this group. 
1959), a finding which we have confirmed in this study. This elevation could either wholly or partly account for the longer and heavier thrombi found in patients with myocardial infarction.

We do not know whether the factor or factors responsible for the development of large thrombi were present before infarction or merely reflect the results of infarction. It appears that the latter is more likely. Nevertheless, it is interesting to speculate whether this propensity to abnormal in vitro thrombosis after myocardial infarction might be associated with the tendency of these patients to subsequent thrombotic episodes.

Our results clearly indicate that there is a significant increase in the incidence of platelet abnormalities in patients with myocardial infarction when compared with control subjects over the age of 40 years. Again we cannot be sure whether these findings relate to a state existing before infarction or are wholly or in part a sequel to myocardial necrosis. However, we have demonstrated that there is a definite tendency for both the frequency of spontaneous platelet aggregation and thrombus size to increase with age in apparently healthy subjects. These findings suggest that the factor or factors responsible for these phenomena are present to some extent before the clinical event, and that coronary thrombosis could result from an exaggeration of this trend.

The overall frequency of platelet abnormality was similar in patients with myocardial infarction whether or not they were receiving anticoagulant therapy (Table II). Two explanations for this finding should be considered. First, it could be that in anticoagulated patients the initial overall frequency of platelet abnormality was greater, and that this frequency has in fact been reduced by therapy. Alternatively, anticoagulants may have had little or no effect on platelet aggregation. On the other hand, there was a trend, though not statistically significant (Table II), for the snowstorm phenomenon to occur more often in anticoagulated patients $(11.5 \%)$ than in those not receiving anticoagulant therapy (4.7\%). At first sight this might suggest that anticoagulant therapy had enhanced platelet aggregation. This trend may, however, merely reflect the fact that those patients selected for anticoagulant therapy differed from those not given anticoagulants, possibly on the basis of more extensive infarction. It is apparent that the effect of oral anticoagulants on platelet aggregation in this in vitro system is inconclusive.

\section{Summary}

Fifty healthy subjects and 52 patients with myocardial infarction were investigated, the Chandler apparatus being used as an in vitro model for the study of thrombosis and platelet aggregation. It was found that thrombus weight and length increased with age in healthy subjects, and that both were markedly elevated in patients with myocardial infarction. Thrombus weight and length were less in patients receiving oral anticoagulant therapy, and both declined progressively with the passage of time after infarction. Plasma fibrinogen levels and thrombus weight showed a statistically significant correlation in both control subjects and in patients with myocardial infarction. No significant correlation between total serum cholesterol levels and thrombus weight was found.

Abnormal platelet aggregation was found to increase in frequency with age in healthy control subjects, and in patients with myocardial infarction it was significantly more common than in control subjects. The overall frequency of abnormal platelet aggregation was slightly less in those patients who had sustained their infarcts more than six weeks before the time of study. Patients receiving oral anticoagulants showed no significant decrease in the frequency of abnormal platelet aggregation, but a trend for the snowstorm phenomenon to occur more often in this group was noted.

This study has shown that the blood of patients with myocardial infarction shows a propensity to abnormal in vitro thrombosis and platelet aggregation. The possible significance of the findings is discussed.

We are pleased to record the support of the National Heart Foundation of Australia and the technical assistance given by Miss J. Bansemer, Mr. C. Lowden, and Miss M. Hall. We also wish to thank Dr. A. E. Taylor for the cholesterol and fibrinogen determinations.

\section{REFERENCES}

Chandler, A. B. (1958). Lab. Invest., 7, 110.

Coles, M., and Roman, W. (1957). Ұ. clin. Path., 10, 282.

Connor, W. E., Poole, J. C. F. (1961). Quart. F. exp. Physiol., 46, 1.

Cunningham, G. M., McNicol, G. P., and Douglas, A. S. (1965). Lancet, $1,729$.

McDonald, L., and Edgill, M. (1959). Ibid., 1, 1115.

Poole, J. C. F. (1959). Quart. F. exp. Physiol., 44, 377.

Zlatkis, A., Zak, B., and Boyle, A. J. (1953). f. Lab. clin. Med., 41, 486.

\title{
Changing Patterns of Fracture in the Dorsal and Lumbar Spine
}

\author{
H. B. GRIFFITH,* M.A., B.M., F.R.C.S., M.R.C.P. ; J. R. W. GLEAVE, † M.A., B.M., F.R.C.S. \\ R. G. TAYLOR, $\ddagger$ M.A., M.CH., F.R.C.S.
}

Brit. med. 7., 1966, 1, 891-894

\begin{abstract}
Major injuries are not new to this country, but their numbers are beginning to reach epidemic proportions with the coming of the motor-car society. Because changing causes of injury may be producing changing patterns of damage we have surveyed fractures of the dorsal and lumbar spine seen by the Accident Service at the Radcliffe Infirmary in the decade ending in 1957. Injuries to the cervical spine in this decade have already been surveyed (Taylor and Gleave, 1962). While injuries to the cervical spine often occur in isolation, fractures of the dorsal and lumbar vertebrae imply a transmission through and absorption by the body of a great deal of kinetic energy. Other parts of the body are more likely to transmit and to absorb force, and will be damaged in so doing. Consequently,
\end{abstract}

we have paid particular attention to the pattern of injuries suffered by the body as a whole and the way in which they impinge on the spinal injury. Further, and related to these multiple injuries, we have come to believe that the thoraco-

* Senior Registrar, Department of Neurological Surgery, Radcliffe Infirmary, Oxford. Present address: Department of Neurosurgery, Royal Infirmary, Manchester.

† Late Senior Registrar, Department of Neurological Surgery, Radcliffe Infirmary, Oxford. Present appointment: Consultant Neurological Surgeon, New Addenbrooke's Hospital, Cambridge.

† Consultant Orthopaedic Surgeon, the Accident Service, Radcliffe Infirmary, Oxford.

Requests for reprints should be sent to Mr. H. B. Griffith, Department of Neurosurgery, Royal Infirmary, Manchester 13. 